\title{
A High-Efficiency Compact Planar Antenna for ISM Wireless Systems
}

\author{
Tao Zhou, ${ }^{1}$ Yazi Cao, ${ }^{1}$ Zhiqun Cheng, ${ }^{1}$ Martine Le Berre, ${ }^{2}$ and Francis Calmon ${ }^{2}$ \\ ${ }^{1}$ Key Lab of RF Circuits and Systems of the Ministry of Education of China, Microelectronics CAD Center, Hangzhou Dianzi University, \\ Hangzhou 310018, China \\ ${ }^{2}$ Institut des Nanotechnologies de Lyon, INL UMR 5270, CNRS, INSA de Lyon, Universite de Lyon, Lyon, France
}

Correspondence should be addressed to Yazi Cao; yazi.cao@hotmail.com

Received 8 November 2016; Revised 16 January 2017; Accepted 7 February 2017; Published 27 February 2017

Academic Editor: Toni Björninen

Copyright (C) 2017 Tao Zhou et al. This is an open access article distributed under the Creative Commons Attribution License, which permits unrestricted use, distribution, and reproduction in any medium, provided the original work is properly cited.

\begin{abstract}
A novel high-efficiency compact planar antenna at $433 \mathrm{MHz}$ with minimized size and low-cost and easy to integrate into the ISM wireless applications is designed, fabricated, and measured. Capacitive strips that are formed by cutting inter-digital slots and the meander lines on both sides are introduced to greatly reduce the antenna size yet maintain the high efficiency. The proposed antenna has a simple planar structure and occupies a small area (i.e., $45 \times 30 \mathrm{~mm}^{2}$ ). This novel electrically small antenna can be operated well without any lumped elements for impedance matching. Details of the antenna design and experimental results are presented and discussed.
\end{abstract}

\section{Introduction}

ISM $433 \mathrm{MHz}$ frequency band is commonly used for low data-rate applications, such as remote control engine start systems, remote keyless entry (RKE) systems, and wireless sensor network (WSN) [1-4]. The most commonly used antennas for these wireless applications are of the helical type because of their small size and good efficiency. However, the helical antennas are incompetent in their mechanical construction and bulky sizes [5]. Moreover, the helical antennas can be readily detuned by nearby objects.

The printed-circuit board (PCB) antennas are another type of commonly used antennas due to their good stability, low-cost, and easy integration. For the traditional designs, these kinds of antennas always occupy large PCB areas in order to operate at ISM $433 \mathrm{MHz}$ frequency bands and are thus hardly to be integrated into the ISM wireless devices that are compact and small [6]. As the antenna size decreases, the radiation resistance decreases whereas the quality factor increases, resulting in low efficiency and narrow bandwidth. Hence, how to reduce the antenna size yet maintain the antenna electronic performance is one of the major challenges.
A meander monopolePCB antenna using the metal shield box was presented in [7], achieving $5 \mathrm{MHz}$ bandwidth and $-4.3 \mathrm{dBi}$ gain, with the total size of $82 \times 51 \mathrm{~mm}^{2}$. This antenna is, however, still too large to be applicable in the compact wireless applications, that is, remote keyless entry systems. $A$ very compact $\mathrm{PCB}$ antenna with dimensions of $51 \times$ $28 \mathrm{~mm}^{2}$ including the ground plane was presented in [8]. However, the significant size reduction was achieved at a cost of significant reduction of the antenna gain to $-13 \mathrm{dBi}$.

In this letter, a novel high-efficiency compact planar antenna at $433 \mathrm{MHz}$ with minimized size and low-cost and easy to integrate into the ISM wireless applications is introduced. The proposed antenna consists of meander lines, a pair of capacitive strips that are formed by cutting inter-digital slots, and the ground plane for the transceiver circuits and the battery. The total antenna dimensions is $80 \times 30 \mathrm{~mm}^{2}$ including the ground plane and the antenna itself that only occupies an area of $45 \times 30 \mathrm{~mm}^{2}$. This electrically small antenna can be operated well without any lumped elements for good impedance matching. The proposed antenna can achieve the $4 \mathrm{MHz}$ bandwidth with the $1.2 \mathrm{dBi}$ measured realized gain at $433 \mathrm{MHz}$. The design considerations and measured 


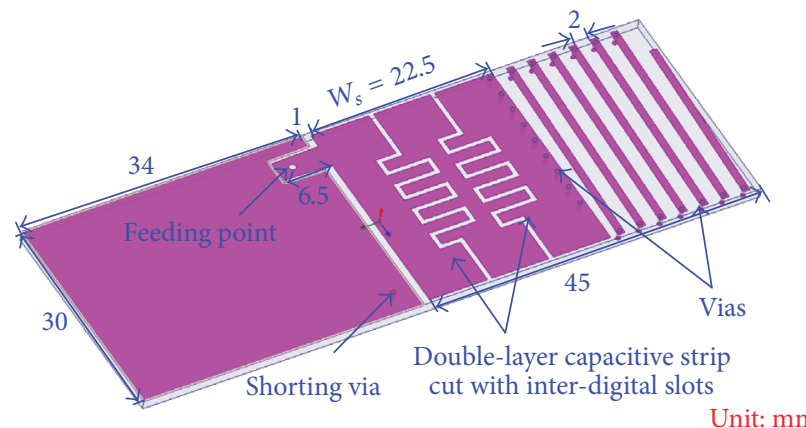

(a)

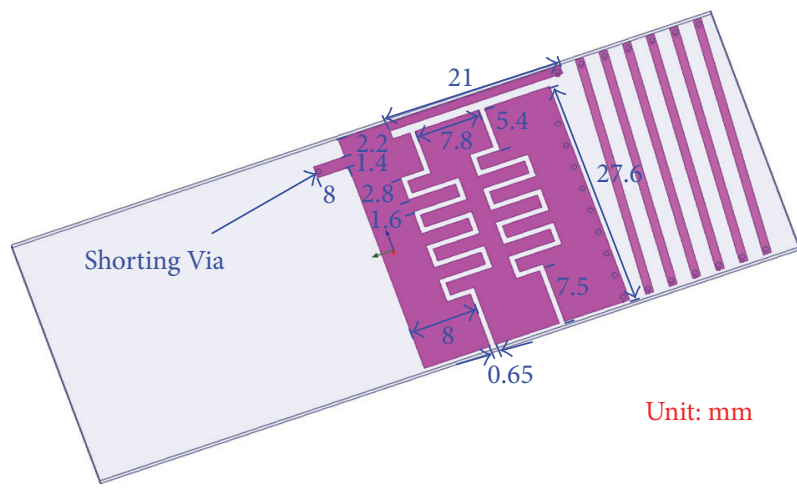

(b)

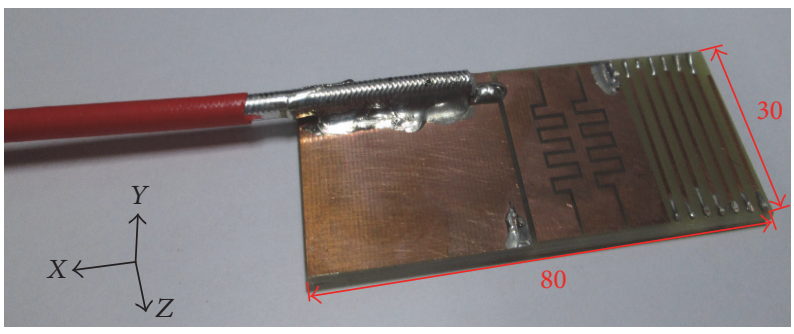

(c)

Figure 1: Configuration of the proposed antenna on a 1.6-mmFR-4 substrate. (a) Top side, (b) bottom side, and (c) photo of the antenna prototype top side.

performances of the proposed antenna are studied and presented.

\section{Antenna Design}

Figure 1 depicts the structure of the proposed planar antenna, which is fabricated on a low-cost double-layer FR4 substrate board. The proposed structure consists of the CPW feeding structure, a pair of coupled capacitive strips, the shorting structure, a double-layer meander line, and the ground plane for the transceiver circuits or the battery. The double-layer meander line with metal width of $1 \mathrm{~mm}$ and gap width of $2 \mathrm{~mm}$ is connected to the capacitive strips and runs around the substrate board through via-holes and finally ends on the top side of the PCB board. The pair of capacitive strips printed on both sides of FR4 substrate board is formed by cutting inter-digital slots on both sides. The ground plane is printed on the front side of the FR4 substrate board. A shorting via connects the ground plane to the back side of the capacitive strips. The ground plane, whose dimensions are $34 \mathrm{~mm}$ in length and $30 \mathrm{~mm}$ in width, is printed on a $1.6 \mathrm{~mm}$ thick FR4 substrate of relative permittivity 4.4 and loss tangent 0.02 . The total area of the proposed antenna is only $45 \times 30 \mathrm{~mm}^{2}$.

The size of the antenna is very compact. The proposed design can be readily integrated with the transceiver circuit, the battery, and the sensor circuit in a small area for the short-range ISM wireless devices. In the traditional designs, it is difficult to match the antenna without any lumped elements. These extra lumped elements used in the matching circuit would cause additional loss and thus degrade antenna efficiency. This novel electrically small antenna can be operated well without using any lumped elements for impedance matching.

Different from [7, 9], a pair of double-layer coupled capacitive strips that are formed by cutting inter-digital slots is introduced to connect between the meander line monopole and the ground plane. The capacitive effects of these interdigital slots cut on the double-layer coupled capacitive strips can provide times of capacitances, thus further reducing the antenna size and also enhancing the impedance matching in the operation frequency range. The double-layer strips, the top and bottom strips, are connected through vias. As shown in Figure 1, the capacitive strips no longer serve as a part of the ground plane. Instead, they serve as a part of the monopole antenna. By doing so, one can further enlarge the matching area and improve the antenna matching and reduce the resonant frequency.

Note that the capacitive strip at bottom can be reused for some battery or sensor circuit if the slots at bottom were removed and only the slots at top were kept. To accommodate the structures into a small volume, the meander lines, which are printed on both sides and connected through small vias, are used in the proposed design. Both the meander lines and the double-layer capacitive strips play an important role in determining the center frequency. Thus, the equivalent circuit of the proposed planar antenna can be modeled as a series-connected LC resonators as shown in Figure 2. Here $Z_{s}$ and $Z_{L}$ represent the input source resistance and freespace loading resistance, respectively. $C_{\text {short }}$ and $L_{\text {short }}$ are used to model the corresponding capacitance and inductance 


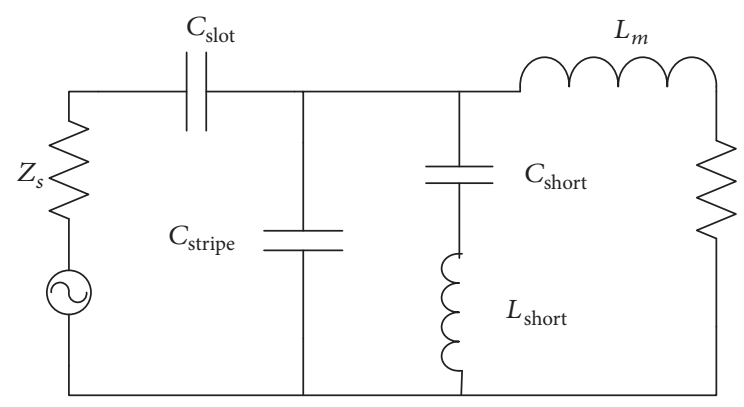

Figure 2: Equivalent circuit model of the proposed antenna.

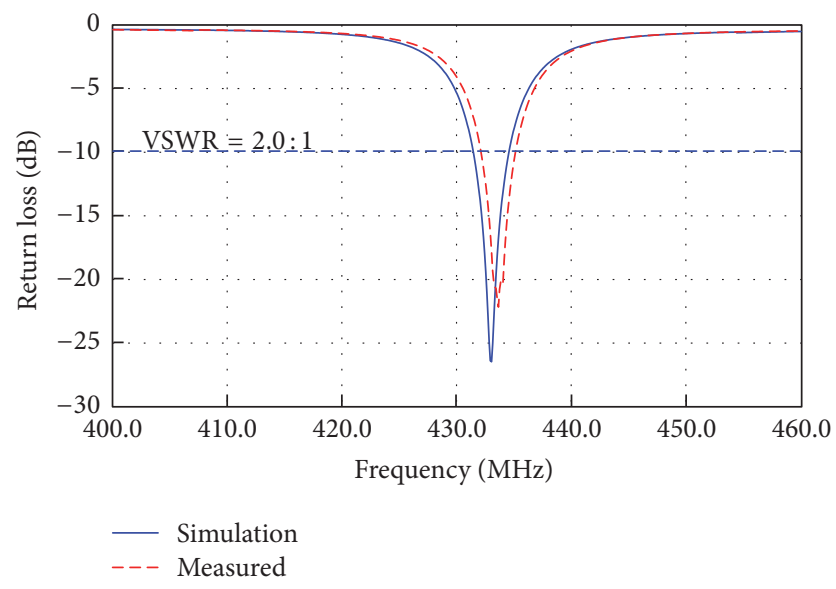

FIgURE 3: Measured and simulated return losses of the proposed antenna.

by the shorting structure. $C_{\text {strip }}$ represents the corresponding capacitance by the pair of double-layer coupled capacitive strips. Different from $[7,9], C_{\text {slot }}$ introduced in this paper represents the corresponding capacitance by the inter-digital slots cut on the coupled strips. $L_{m}$ is to model the inductance generated by the double-layer meander line. From Figure 2, the resonant frequency of the proposed antenna can be by adjusting the shorting structure, the meander lines, and the double-layer capacitive strips.

\section{Experimental Results and Discussions}

Figure 3 plots the measured and simulated return losses of the proposed planar antenna with the dimensions given in Figure 1. In order to minimize the feed cable's effect in the return loss measurement, the coaxial cable connecting the proposed antenna to the Agilent E5071 Network analyzer is loaded with ferrite beads. The measured data agree well with the simulated results from the Ansoft simulation software HFSS [10] which used the lumped port excitation in the 3D simulation. The measured center frequency of the proposed antenna is $433 \mathrm{MHz}$ and the measured 2:1 VSWR (-10 dB return loss) bandwidth is $4 \mathrm{MHz}(431 \sim 435 \mathrm{MHz})$, covering the ISM 433 operational band. This novel electrically small antenna can be operated well without lumped elements for impedance matching as shown in Figure 1.

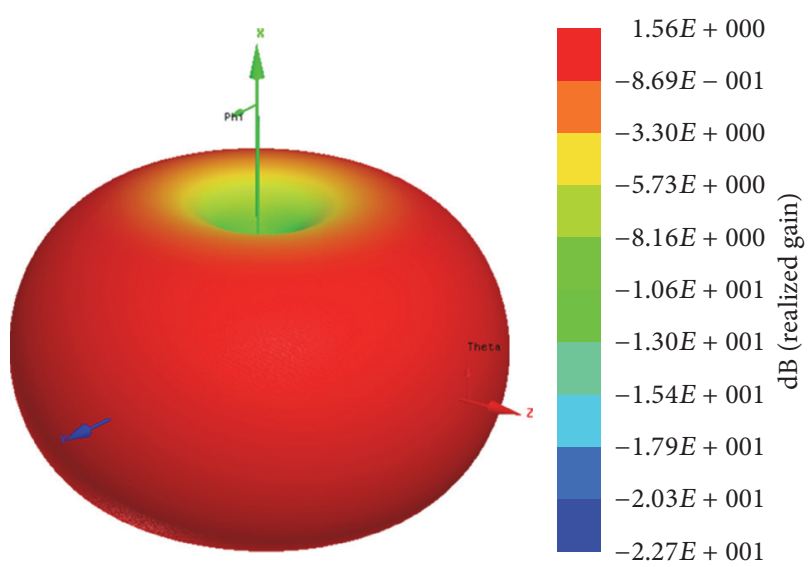

FIGURE 4: Simulated 3D radiation patterns of the proposed antenna at $433 \mathrm{MHz}$.

TABLE 1: Comparison of various antennas.

\begin{tabular}{lcc}
\hline Antenna type & Total size $\left(\mathrm{mm}^{2}\right)$ & $\begin{array}{c}\text { Measured gain } \\
(\mathrm{dBi})\end{array}$ \\
\hline Helical antenna [5] & $\begin{array}{c}35.35 \times 8.15(\psi)+ \\
\text { Extra Ground }\end{array}$ & -5 \\
$\begin{array}{l}\text { Square-spiral antenna [8] } \\
\text { Metal-shielding box }\end{array}$ & $51 \times 28$ & -13 \\
antenna [7] & $82 \times 51$ & -4.3 \\
$\begin{array}{l}\text { Meander-line antenna [9] } \\
\text { Proposed antenna }\end{array}$ & $86 \times 50$ & -0.7 \\
\hline
\end{tabular}

The simulated three-dimensional (3D) gain pattern at $433 \mathrm{MHz}$ of the fabricated prototype is shown in Figure 4. The simulated and measured maximum realized gains at $433 \mathrm{MHz}$ are $1.5 \mathrm{dBi}$ and $1.2 \mathrm{dBi}$, respectively, which is in a good agreement. And the radiation efficiency at $433 \mathrm{MHz}$ is $60.8 \%$. The measured gain radiation patterns in the E-plane and the $H$-plane at $433 \mathrm{MHz}$ are shown in Figure 5 for the fabricated prototype. At $433 \mathrm{MHz}$, a bidirectional pattern is achieved in the E-plane (i.e., the $X Z$ plane) whereas a good omni-directional radiation patterns is observed in the $H$ plane (i.e., the $Y Z$ plane). The polarization level is larger than $20 \mathrm{~dB}$.

Table 1 compares the measured peak gains of the proposed planar antenna with those of other antennas in the literature. Compared to $[7,9]$, the introduced capacitive effects of these inter-digital slots cut on the double-layer coupled capacitive strips can provide times of capacitances, thus further reducing the antenna size and also enhancing the impedance matching in the operation frequency range. The double-layer coupled capacitive strips with inter-digital slots are not only working as the matching element but also working as a part of the radiating elements. So for a given similar size, it has more spaces for the other radiating elements, that is, the meander lines printed on the double layers. As is illustrated in Table 1, the proposed antenna achieves the best realized gain and radiation efficiency among all these antennas in Table 1. 


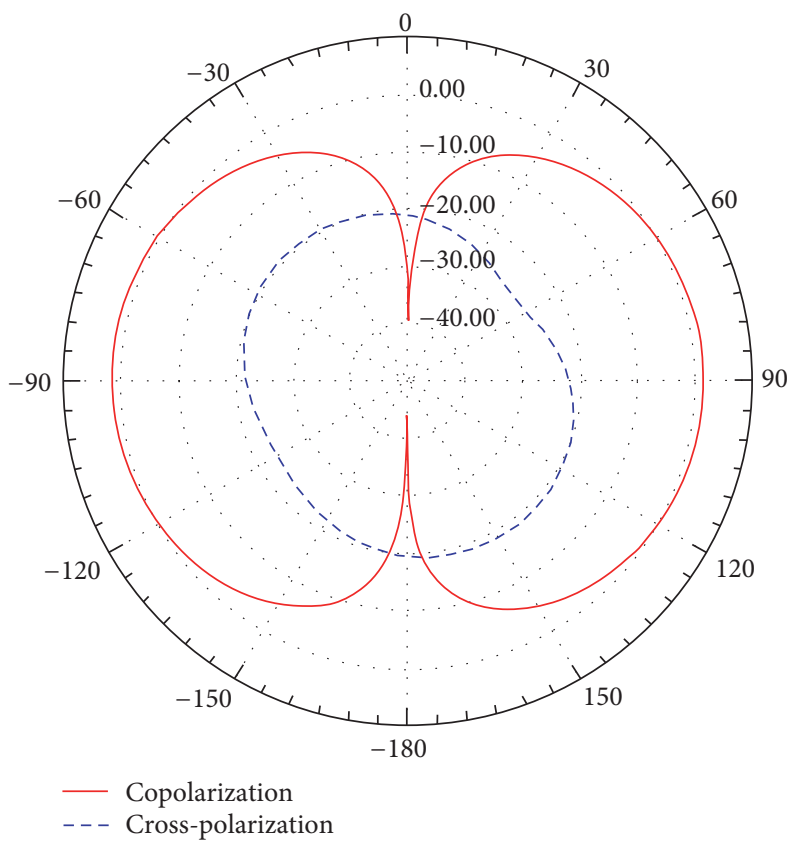

(a)

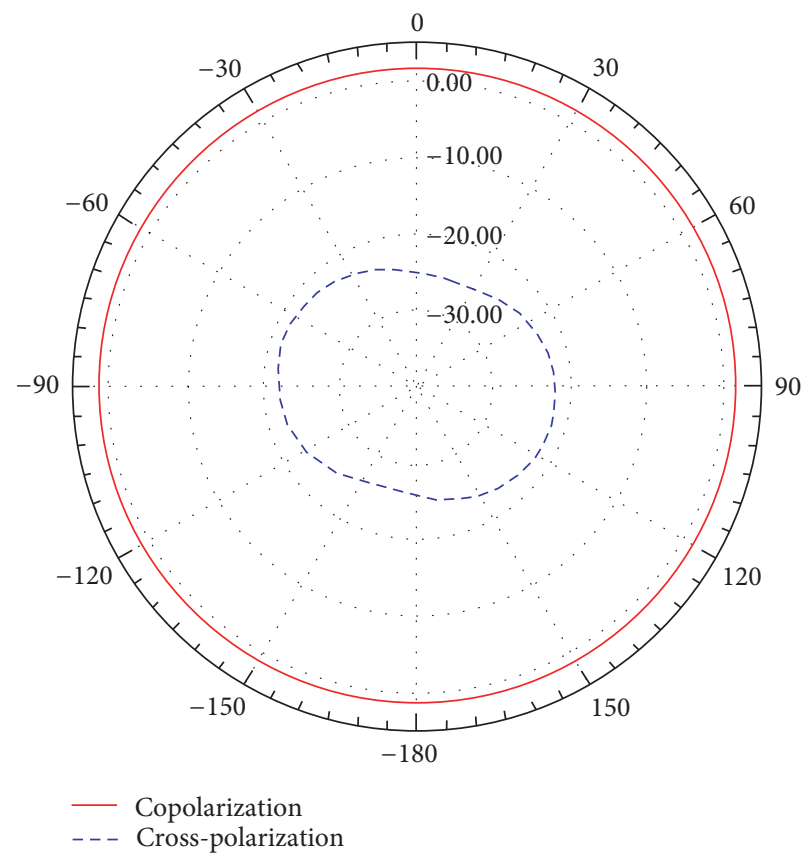

(b)

FIGURE 5: Measured radiation patterns of the proposed antenna at $433 \mathrm{MHz}$ (a) E-plane (i.e, $X Z$ plane) and (b) $H$-plane (i.e., $Y Z$ plane).

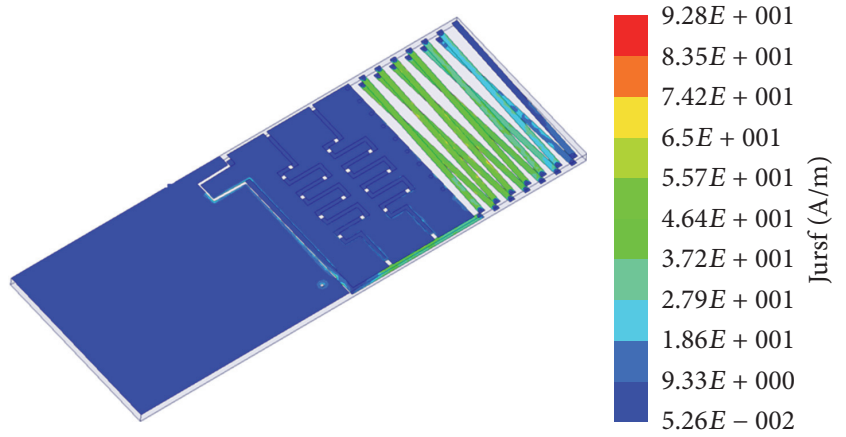

FIGURE 6: Simulated current distributions of the proposed antenna at $433 \mathrm{MHz}$.

Figure 6 depicts the simulated surface current distribution at $433 \mathrm{MHz}$. From Figure 6, one can see that large currents flow in the capacitive strips and the meander lines. Analysis reveals that the resonant frequency is primarily determined by the total length of the meander line and the capacitive strip width $W_{s}$.

The capacitive strips that are formed by cutting interdigital slots play an important role in determining the center frequency and the impedance matching. Figure 7 depicts the simulated return losses versus the width $W_{s}$ of the capacitive strip. As shown in Figure 7, one can observe a large frequency-shifting effect due to different width $W_{s}$. Hence, the resonant frequency can be controlled readily and precisely by adjusting $W_{s}$.

In order to show the effect of inter-digital slots on the matching performance, Figure 8 depicts the simulated return

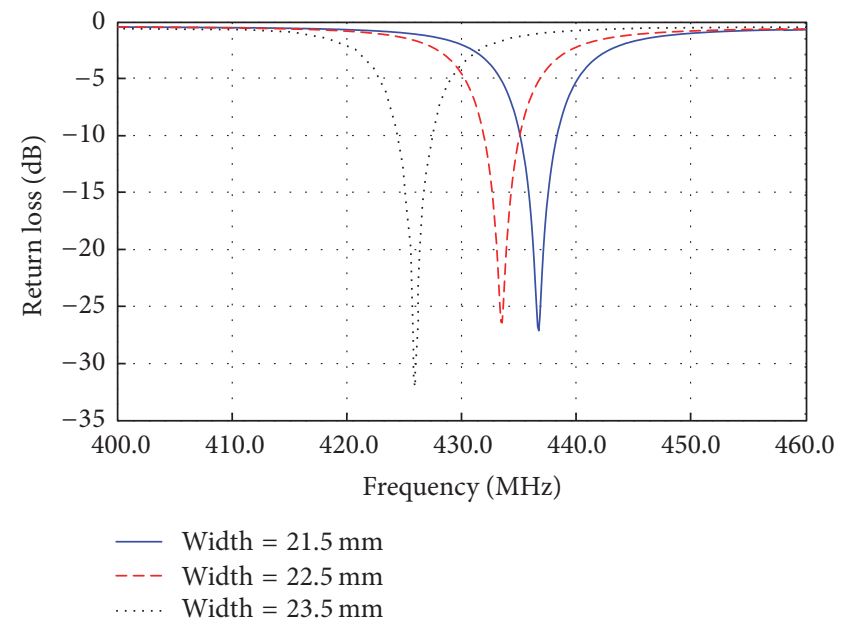

FIgURE 7: Simulated return losses of the proposed antenna with variations of the capacitive strip width $W_{s}$.

losses versus the capacitive strips with and without interdigital slots. As shown in Figure 8, one can observe that the inherent capacitance generated by these inter-digital slots can greatly improve the impedance matching and also reduce the resonant frequency as expected. This novel electrically small antenna can thus be operated well without any lumped elements for good impedance matching.

\section{Conclusion}

A new compact planar antenna was introduced for ISM wireless applications. A prototype of the proposed antenna 


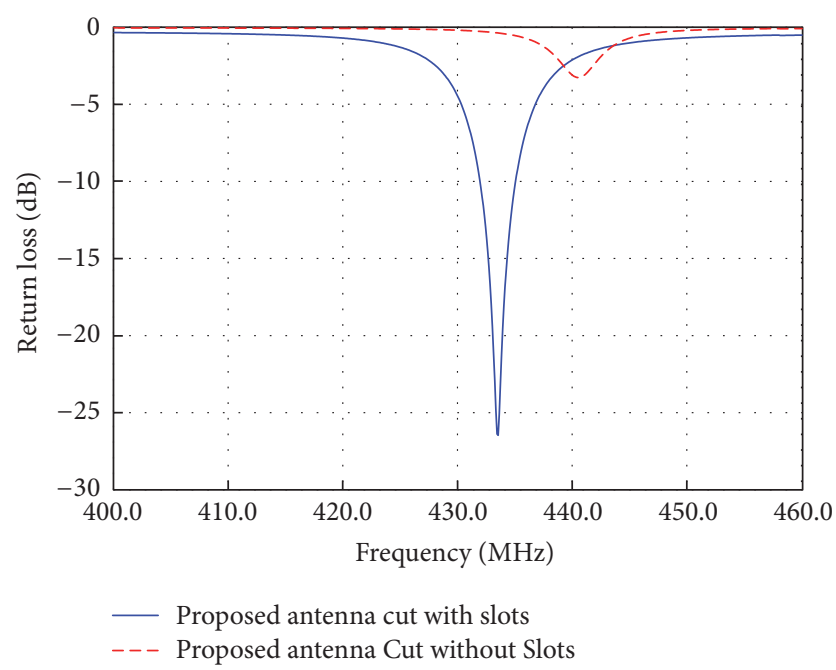

FIGURE 8: Simulated return loss of the proposed antenna cut with and without slots.

has been successfully designed and fabricated. This novel antenna has a simple planar structure of a small size, that is, 45 $\times 30 \mathrm{~mm}^{2}$. A pair of coupled capacitive strips that are formed by cutting inter-digital shots has been introduced to improve the impedance matching and reduce the resonant frequency. This novel electrically small antenna can be operated well without using any lumped elements for impedance matching. The proposed antenna has a relative small size yet achieves high realized gain and radiation efficiency, which can be widely used in remote control engine start systems, remote keyless entry systems, and wireless sensor network.

\section{Competing Interests}

The authors declare that they have no competing interests.

\section{Acknowledgments}

This work was supported by the National Nature Science Foundation of China under Grants nos. 61411136003 and 61331007 and the Zhejiang Provincial Natural Science Foundation of China under Grant no. LZ14F040001.

\section{References}

[1] E.-S. Yang and H.-W. Son, "Dual-polarised metal-mountable UHF RFID tag antenna for polarisation diversity," Electronics Letters, vol. 52, no. 7, pp. 496-498, 2016.

[2] A. Farswan, A. K. Gautam, B. Kanaujia, and K. Rambabu, "Design of Koch fractal circularly polarized antenna for handheld UHF RFID reader applications," IEEE Transactions on Antennas and Propagation, vol. 64, no. 2, pp. 771-775, 2016.

[3] Y.-F. Lin, M.-J. Chang, H.-M. Chen, and B.-Y. Lai, "Gain enhancement of ground radiation antenna for RFID tag mounted on metallic plane," Institute of Electrical and Electronics Engineers. Transactions on Antennas and Propagation, vol. 64, no. 4, pp. 1193-1200, 2016.
[4] P. Soboll, V. Wienstroer, and R. Kronberger, "Innovating RFID for future applications: a capacitive coupled antenna design for UHF RFID application," IEEE Microwave Magazine, vol. 17, no. 2, pp. 65-69, 2016.

[5] Pulse Finland Oy, ISM Helical Antenna, Datasheet Version, 2008.

[6] H. K. Ryu, S. Lim, and J. M. Woo, "Design of electrically small, folded monopole antenna using C-shaped meander for active $433.92 \mathrm{MHz}$ RFID tag in metallic container application," Electronics Letters, vol. 44, no. 25, pp. 1445-1447, 2008.

[7] W. Liu, Z. Zhang, and Z. Feng, "ISM 433-MHz miniaturized antenna using the shielding box of mobile terminals," IEEE Antennas and Wireless Propagation Letters, vol. 11, pp. 330-333, 2012.

[8] J. Buckley, D. Gaetano, K. G. McCarthy, L. Loizou, B. O’Flynn, and C. O'Mathuna, "Compact $433 \mathrm{MHz}$ antenna for wireless smart system applications," Electronics Letters, vol. 50, no. 8, pp. 572-574, 2014.

[9] C. T. Rodenbeck, "Planar miniature RFID antennas suitable for integration with batteries," IEEE Transactions on Antennas and Propagation, vol. 54, no. 12, pp. 3700-3706, 2006.

[10] HFSS Version 17, ANSYS, Canonsburg, Pa, USA, 2016. 


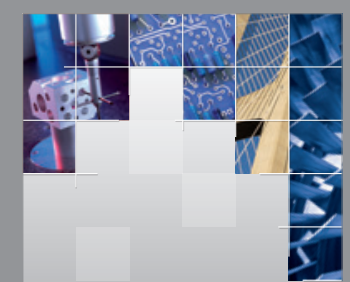

\section{Enfincering}
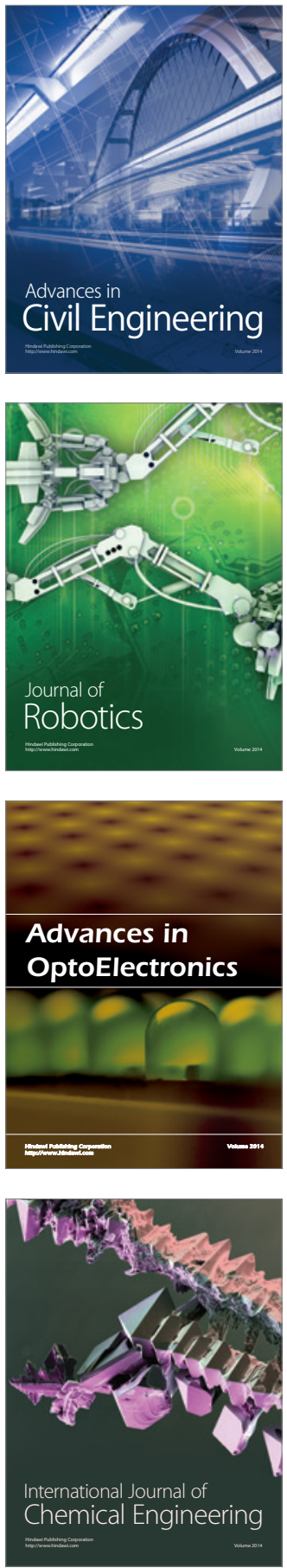

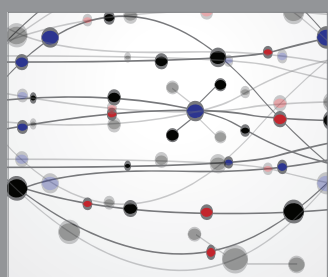

The Scientific World Journal

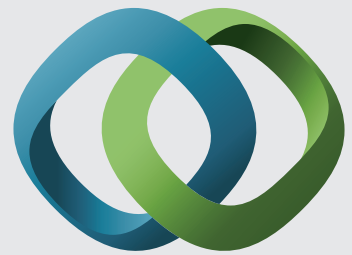

\section{Hindawi}

Submit your manuscripts at

https://www.hindawi.com
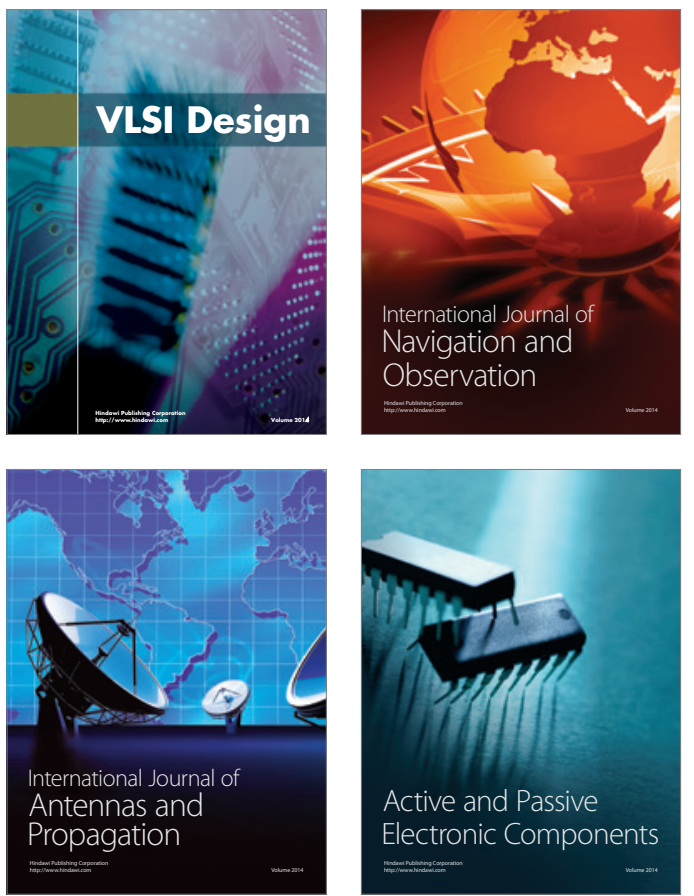
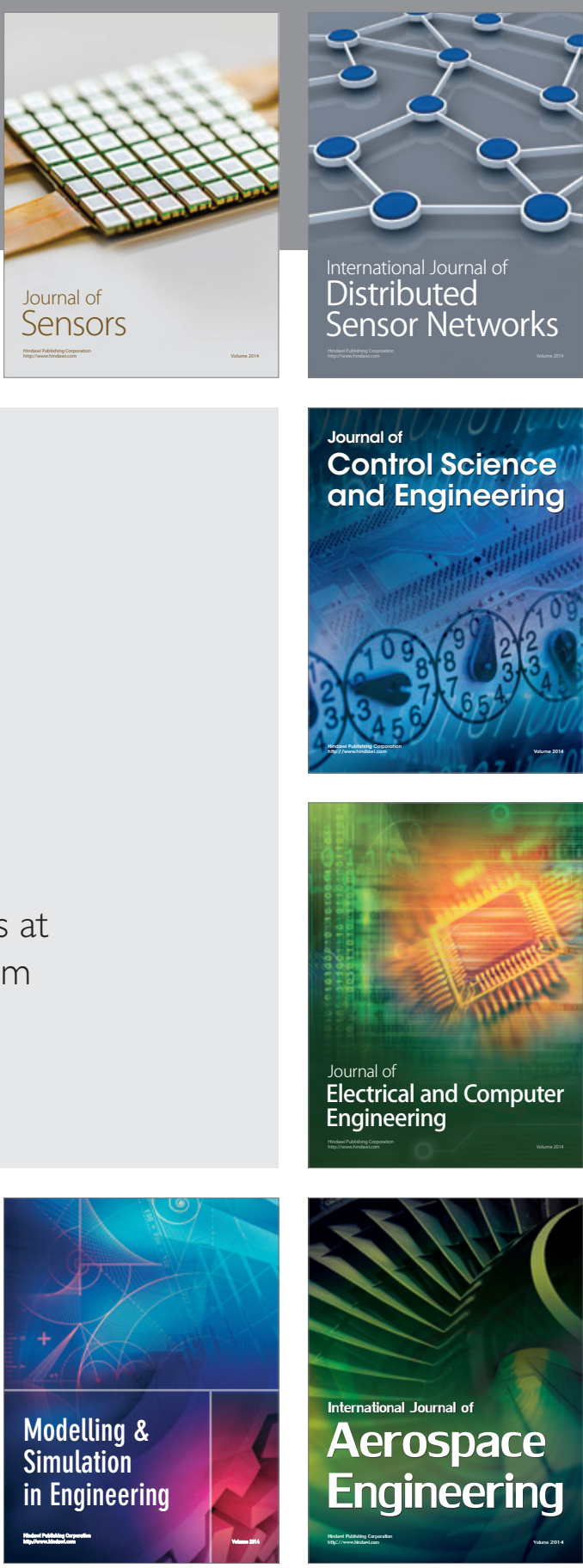

International Journal of

Distributed

Sensor Networks

$-$

Joumal of

Control Science

and Engineering
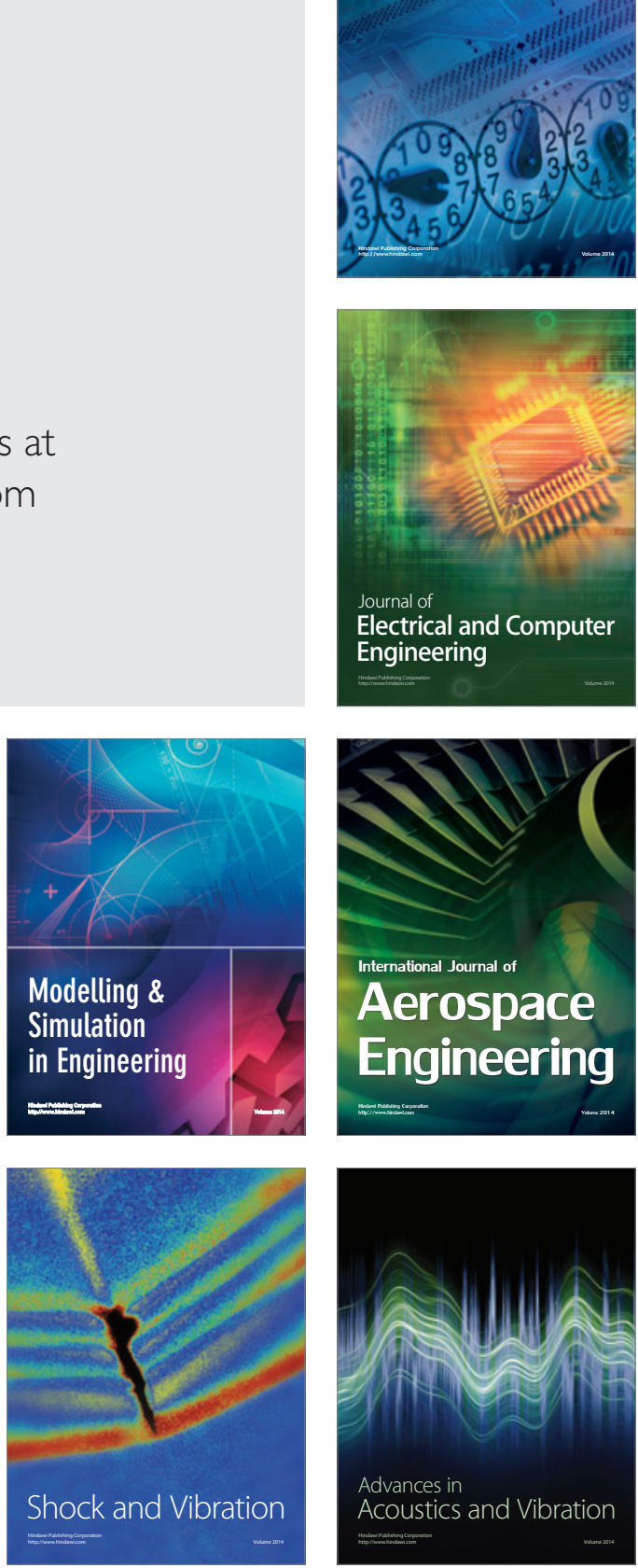